\title{
REGULARIZAÇÃO FUNDIÁRIA URBANA: E A LEGALIZAÇÃO DOS LOTEAMENTOS URBANOS
}

\author{
URBAN LAND SETTLEMENT: AND THE \\ LEGALIZATION OF URBAN ALLOTMENTS
}

\section{Débora Motta ${ }^{1}$}

Resumo: O objetivo geral do presente artigo é compreender o instituto da Regularização Fundiária, sua importância no cotidiano e a repercussão sobre os direitos fundamentais constitucionais, a fim de abordar a Regularização Fundiária Urbana decorrente dos loteamentos irregulares e clandestinos, de acordo com a Lei n. 13.465/2017 (Lei de Regularização Fundiária Rural e Urbana); a Resolução n. 8/2014, do Estado de Santa Catarina; e a Lei Complementar n. 337/2016, do Município de Herval d'Oeste. Frisa-se que o desrespeito às leis federais, estaduais e municipais fez com que os adquirentes passassem a construir e residir em suas habitações nas suas propriedades, porém, em razão da irregularidade da criação dos loteamentos e desmembramentos, não podem registrá-las devidamente em seus respectivos nomes. Trata-se de pesquisa bibliográfica, realizada pelo método dedutivo, baseada na fundamentação doutrinária, aplicação da legislação especial sobre a Regularização Fundiária federal, estadual e municipal, artigos científicos e entendimentos jurisprudenciais. Assim, preten-

1 Pós-Graduanda de nível de especialização em Direito Público e Privado pela Escola Superior da Magistratura do Estado de Santa Catarina (ESMESC). Graduada em Direito pela Universidade do Oeste de Santa Catarina (UNOESC), campus de Joaçaba. Residente Judicial da Vara Criminal da Comarca de Joaçaba/SC. E-mail: deboramottadto@outlook.com. 
de-se demonstrar a possibilidade de transformar as propriedades consideradas "informais" ou "clandestinas" em loteamentos legítimos, segundo a legislação vigente e de acordo com a aplicação dos direitos fundamentais da propriedade, da moradia e da dignidade da pessoa humana.

Palavras-chave: Regularização Fundiária Urbana. Loteamento Irregular. Dignidade da Pessoa Humana. Direito à Moradia. Direito à Propriedade.

Abstract: The general objective of this article is to understand the Institute of Land Regularization, its importance in our daily lives and the repercussion on fundamental constitutional rights, aiming to address urban land regularization resulting from irregular and clandestine allotments, according to the Law of rural and urban Land Regularization n. 13.465/2017, Resolution n. $8 / 2014$ of the State of Santa Catarina and Complementary Law n. $337 / 2016$ of the Municipality of Herval D'Oeste. It should be em- phasized that the disrespect of federal, state, and municipal laws, caused the acquirers to build and reside their dwellings in their properties, however, due to the irregularity of the creation of allotments and dismemberments, they cannot properly register them in their respective names. This is a bibliographical research, carried out by the deductive method, based on doctrinal foundation, application of special legislation on federal, state and municipal land regularization, scientific articles, and jurisprudential understandings. Thus, it is intended to demonstrate the possibility of transforming properties considered "informal" or "clandestine" into legitimate allotments, according to current legislation and following the application of the fundamental rights of property, housing, and the dignity of the human person.

Keywords: Urban Land Regularization. Irregular Allotment. Dignity of the Human Person. Right to Housing. Right to Pro-

\section{INTRODUÇÃO}

Desde o intensificado desenvolvimento das cidades, o êxodo rural, motivado pela expectativa de uma vida melhor nos centros urbanos, mostrou ser um fenômeno de grandes pro- 
porções. Isso, além de mudar o espaço geográfico brasileiro, tornando-o cada vez mais urbano, gerou a ocupação irregular de diversas áreas, algumas, inclusive, consideradas de proteção ecológica.

Em razão desse movimento e de não ter sido objeto imediato das políticas públicas governamentais, ocorreu a ocupação desenfreada dos espaços "vazios" das cidades, causando graves problemas de ocupação. O novo desafio passou a ser o desenvolvimento de políticas públicas voltadas a garantir moradia digna para todos os seus habitantes, de forma regular, atendendo a questões de saúde pública e sanitárias.

Em decorrência do exposto, o direito se viu obrigado a regularizar essa situação, nascendo, assim, o direito urbanístico, conjugado com o direito imobiliário, ensejando a criação do instituto da Regularização Fundiária, processo pelo qual seriam adotadas as medidas ambientais, urbanísticas, sociais e jurídicas mais adequadas para a efetivação da regularização das propriedades urbanas irregulares e clandestinas, obedecendo aos parâmetros das legislações federal, estadual e, sobretudo, municipal.

A primeira legislação sobre o tema foi a Lei n. 601, de 1850, conhecida por Lei de Terra, que se tratava de legislação específica para a questão fundiária (TARTUCE, 2018). Atualmente, após mais de um século, a legislação vigente é a Lei $n$. 13.465/17, criada para regulamentar o art. 182 da Constituição Federal de 1988, cerne da política urbana nacional e que trouxe como principais objetivos a garantia do bem-estar, da segurança e do equilíbrio ambiental aos municípios e aos seus habitantes (SANTIN; COMIRAN, 2018).

Portanto, o presente estudo busca, por meio da doutrina, das normas legislativas vigentes e dos entendimentos jurisprudenciais, delimitar a possibilidade do registro das propriedades urbanas, decorrente dos loteamentos irregulares e clandestinos, 
provenientes de uma situação pública e social que necessita incremento do Poder Público e, inevitavelmente, resoluções por meio do Poder Judiciário.

\section{REGULARIZAÇÃO FUNDIÁRIA URBANA}

Considerando o tamanho territorial brasileiro, é inevitável a afirmação de que um dos maiores desafios encontrado por inúmeras cidades são as crises habitacionais, uma vez que os centros urbanos são abarrotados de habitações sem a mínima adequabilidade.

Dificilmente, poder-se-á traçar uma comparação entre as crises habitacionais das grandes metrópoles, como São Paulo, Rio de Janeiro ou Florianópolis, com as de um pequeno Município ao norte do Estado de Santa Catarina. Todavia, independentemente do local em que o indivíduo se encontra, pouco provável que não encontre pelo menos um caso de propriedade irregular que demandará aquisição originária por meio da Justiça, seja por preencher requisitos da usucapião ou por ser um loteamento que não seguiu devidamente as normas do parcelamento de solo.

Rigorosamente falando, a falta de incremento de políticas públicas nas questões habitacionais gera a construção de moradias desprovidas de condições dignas, em locais inadequados e sem saneamento básico.

Dentro desse quadro, é necessário contextualizar os direitos inerentes a todos os indivíduos, de modo a compreender o respaldo constitucional sobre a presente temática.

\subsection{Garantias constitucionais}

Inicialmente, a Constituição garante no bojo de seu art. $5^{\circ}$, caput, que "[...] todos são iguais perante a lei, sem distinção de qualquer natureza, garantindo-se aos brasileiros e aos estrangeiros residentes no País a inviolabilidade do direito à 
vida, à liberdade, à igualdade, à segurança e à propriedade [...]". Verifica-se, nesse dispositivo e em seu inciso XXII, expressa garantia do direito fundamental à propriedade (BRASIL, 1988, grifo nosso).

Entende-se por direito à propriedade o direito patrimonial que possui os indivíduos na sociedade. Esse direito é um dos valores constitucionais mais importantes, bem como é:

[...] um dos pilares dos direitos fundamentais da pessoa humana e ninguém poderá ser destituído de seu patrimônio sem a correspondente e justa indenização. A garantia ao direito de propriedade propicia a efetivação de outros direitos individuais e liberdades, tais como o direito à intimidade, à privacidade, ao lazer, à moradia, à autonomia individual e à preservação da espécie humana. (FERRAZ FILHO et al., 2020, p. 24).

Salienta-se ainda que a constituição frisou, no art. $5^{\circ}$, inciso XIII, uma limitação ao direito à propriedade, qual seja, atender à sua função social, pois a propriedade:

[...] não existe para satisfazer unicamente o titular do seu direito. Não. A satisfação do seu titular está condicionada à destinação social da propriedade. Isso é ainda mais evidente nos dias atuais, em que se toma tanto cuidado com o ambiente ecológico. O desvirtuamento da função social da propriedade pode provocar a sua expropriação por interesse coletivo. Esse é o verdadeiro sentido do inciso em comento. Enfim, não pode o proprietário beneficiar-se do seu bem a dano do interesse social. (FERRAZ FILHO et al., 2020, p. 24-25).

Dito isso, sabe-se que, embora a solução dos conflitos sociais tenha nascido junto aos avanços incessantes da indústria, decorrentes das ideias da função social da propriedade, e seu funcionamento como instituto tenham sido iniciado, em 1891, pelo Papa Leão XIII, no Brasil somente houve início concreto 
a partir da Emenda Constitucional n. 1, de 1969. Com efeito, a Emenda tornou-a cláusula pétrea e princípio cardeal da ordem econômica (arts. $5^{\circ}$, XXIII, e 170, III, da CF), isto é, no texto constitucional, a função social da propriedade passou a ser considerada garantia fundamental no mesmo patamar hierárquico do direito à propriedade (MELO et al., 2018, p. 109).

Assim, de acordo com Melo et al. (2018, p. 111):

[...] não há mais espaço para entender a propriedade divorciada do elemento que lhe confere conteúdo e tutela jurídica, que vem a ser o exercício do domínio mediante a atenta observância da função social, pois, em que pese a proteção de ordem privada da propriedade, ela deverá retratar uma finalidade econômica e social apta a sua vocação urbana ou rural, gerando frutos, empregos e conduzindo a uma justa circulação das riquezas, de modo a que tenhamos uma sociedade mais justa e solidária, objetivo primaz do estado democrático de direito deflagrado pela Constituição da República Federativa do Brasil de 1988.

Aliado a isso, a efetiva tutela dos direitos individuais dos proprietários junto à ponderação dos demais direitos inerentes mostra-se um relevante equilíbrio na busca da proteção dos direitos fundamentais, objetivando não sacrificar em demasia a proteção de um valor em desfavor do outro (MELO et al., 2018, p. 109).

De efeito, a função social da propriedade imobiliária urbana é observada, principalmente, a partir do atendimento do direito social fundamental da moradia (art. $6^{\circ}, \mathrm{CF}$ ), pois se percebe que há a necessidade de medidas econômicas e políticas para se reduzir as desigualdades sociais e regionais, de modo que tanto o direito constitucional quanto o infraconstitucional passe a assegurar "Direitos de Proprietário" a quem ainda não os titulariza (MELO et al., 2018, p. 109-110). 
Ademais, visando que o proprietário do imóvel urbano, decorrente de qualquer modalidade aquisitiva, atenda devidamente à função social, a Constituição (art. 182, § $4^{\circ}$, II) e o Estatuto da Cidade (art. $5^{\circ}$ e $7^{\circ}$ da Lei n. 10.257/2001) utilizam-se de instrumentos jurídicos e políticos que visam à sua concretização.

Dessa forma, verifica-se a disposição, por exemplo, da possibilidade da cobrança do IPTU progressivamente de acordo com a recalcitrância do titular em dar função social à propriedade, aumentando seu valor pelo prazo de cinco anos (MELO et al., 2018, p. 110).

Outra alteração importante foi a inserção da Emenda Constitucional n. 81, de 2014, no art. 243 da Constituição Federal. Nela se possibilitou que as propriedades que tivessem plantio ilegal de plantas psicotrópicas, bem como as que fizessem a exploração de trabalho escravo, sofreriam o confisco, e posteriormente o bem deveria ser destinado à reforma agrária ou a programas habitacionais (MELO et al., 2018, p. 111).

Desse modo, verifica-se que a intervenção do Estado é imprescindível quando não verificada a aplicação do direito à propriedade, de maneira que se pune a conduta e destinam-se os bens ao devido cumprimento da função social originária, qual seja, direito à propriedade para fins de moradia.

Considerando o anteriormente exposto, a Constituição enumerou exemplificativamente uma série de direitos sociais aos seus cidadãos, como é o exemplo do direito à moradia, in verbis:

Art. $6^{\circ}$ São direitos sociais a educação, a saúde, a alimentação, o trabalho, a moradia, o transporte, o lazer, a segurança, a previdência social, a proteção à maternidade e à infância, a assistência aos desamparados, na forma desta Constituição. (BRASIL, 1988). 
Verifica-se que tal dispositivo comporta-se com "[...] direitos de crédito do cidadão[...]", pois envolve o poder de exigir um comportamento ativo por parte do Estado, o qual deve, como sujeito passivo da obrigação, proporcionar ao cidadão as garantias delineadas no dispositivo do art. $6^{\circ}$ da CRFB/88, entre outros direitos constitucionais (VITORINO et al., 2020, p. 54).

Sobre o tema, Souza (2004, p. 45) entende que o exercício primordial dos direitos, essencialmente o direito à moradia, é demonstrado pelo desejo do indivíduo de estabelecer o lugar ao qual se vincula. Entende ainda que os conceitos de moradia e habitação, aparentemente sinônimos, se distinguem pelos efeitos causados, como por exemplo, em relação ao tempo em que a pessoa física tem ou não ânimo de permanecer. Na habitação, o seu exercício se dá de forma temporária e acidental, enquanto o caso da moradia consiste em um ato inseparável à vontade da pessoa natural em se fixar em um lugar determinado de forma definitiva, incluindo a fixação dos interesses da vida cotidiana (SOUZA, 2004, p. 44-45 e p. 141-142).

Em relação à diferença existente entre os direitos fundamentais dispostos no art. $5^{\circ}$ da Constituição, como é o caso do direito à propriedade, e os direitos sociais previstos no art. $6^{\circ}$, caso do direito à moradia, observa-se que tanto a doutrina quanto a jurisprudência não possuem uma tese clara. Contudo, partindo do entendimento de que o art. $5^{\circ}$ possui aplicação imediata, os direitos sociais atendem a critérios de preferência.

Dessa maneira, é utópico dizer que o direito à moradia possui aplicação imediata, pois, caso o fosse, não haveria pessoas sem habitação, pois o Estado a forneceria. Todavia, essa questão adentra na estrutura financeira estatal, na qual o Estado conta com uma série de repartições de receitas, de diversas origens, bem como outras políticas públicas que precisam ser 
atendidas, não podendo o Estado cumprir, imediatamente, o direito social da moradia, gastando tudo o que dispõe para suprir o problema habitacional existente. Logo, a aplicação imediata dos direitos sociais mostra-se "ideologicamente insustentável e financeiramente inviável" (BÉO et al., 2020, p. 51-52).

Assim, Béo et al. (2020, p. 51-52) entendem que apenas as liberdades são de fato direitos de eficácia imediata, enquanto os demais direitos prestativos pelo Estado são valores de eficácia prolongada, exequíveis no tempo, criadas para ajudar a população no desenvolvimento de suas potencialidades naturais, enquanto o Estado continua a exercer seu papel de suprir as necessidades mais fundamentais da pessoa humana.

Considerando que o direito social à moradia é também um direito fundamental constitucional, a União editou a Lei federal n. 7.196/1984, conhecida como Plano Nacional de Moradia, junto ao Sistema Financeiro de Habitação, que cuida dos recursos para a aquisição da casa própria, objetivando promover a regularização das condições habitacionais (BÉO et al., 2020, p. 152).

Inclui-se, ainda, nesse direito explícito, a implementação de saneamento básico, condição essencial e adequada para o conforto habitacional e para a preservação à saúde dos indivíduos. $\mathrm{O}$ atendimento dessa necessidade básica, alcançada por meio de várias práticas públicas e privadas, assegura também o cumprimento do princípio da dignidade da pessoa humana, previsto no art. $1^{\circ}$, inciso III, da Constituição Federal, bem como poderá ocasionar a diminuição das desigualdades sociais, objetivo presente no art. $3^{\circ}$, III, da Constituição Federal (BÉO et al., 2020, p. 184-185).

Nesse sentido, a Constituição dispõe:

Art. $1^{\circ}$ A República Federativa do Brasil, formada pela união indissolúvel dos Estados e Municípios e do Distri- 
to Federal, constitui-se em Estado Democrático de Direito e tem como fundamentos: [...] III - a dignidade da pessoa humana; (BRASIL, 1988).

Esse princípio, mais abrangente, é um dos fundamentos do Estado Democrático de Direito, o qual, junto à atuação do Estado na ordem econômica, na valorização do trabalho e na livre iniciativa, busca assegurar a redução das desigualdades sociais e o pleno emprego (art. 170, VII e VIII, da CF). Outrossim, possibilita a todos uma existência digna, conforme os ditames da ordem social (VITORINO et al., 2020, p. 54-55).

Segundo Almeida et al. (2020, p. 52), sendo esse princípio o terceiro fundamento da República Federativa do Brasil, demonstra-se que a proteção e a promoção da dignidade da pessoa humana são os maiores objetivos do princípio da legalidade.

Pois bem, esse princípio é o carro-chefe dos direitos fundamentais, pois ele engloba a violação dos demais direitos, ou seja, ao não haver a concretização adequada da propriedade e da moradia, questões como desigualdade, pobreza, saúde, esgoto, requisitos mínimos e adequados para uma vida em sociedade são colocados em tela.

Assim, em decorrência do crescimento rápido e sem planejamento das cidades brasileiras, os habitantes são colocados sob condições subumanas, sem o mínimo para sua existência com dignidade, como, por exemplo, acesso à água, à luz, ao saneamento básico, ao transporte público e à saúde, desequilibrando qualquer noção de igualdade e de dignidade (SANTIN; COMIRAN, 2018, p.1599 e p.1606).

É de sua importância que o reconhecimento do direito real à propriedade ou ao uso, por meio da regularização fundiária, objetive a garantia do direito à moradia das famílias, bem como o investimento em infraestrutura e em políticas e serviços públicos capazes de garantir uma habitação com o mínimo 
de dignidade e qualidade de vida. Atende-se, assim, aos três princípios fundamentais aqui estudados, qual seja: direito à propriedade, à moradia e à dignidade da pessoa humana.

\subsection{Loteamento Irregular e Clandestino}

Considerando a história brasileira, a distribuição de terras nunca foi uma questão de fácil resolução. Tanto em relação aos portugueses e aos índios e, depois, aos fazendeiros e aos escravos. A diferença é que antes as questões ocorriam sobre propriedades rurais, fontes da riqueza do país.

Atualmente, os problemas do passado acabaram se repetindo no âmbito urbano, levando a surgir, na maioria dos Municípios brasileiros, habitações em situações precárias, especialmente em favelas, hoje denominadas comunidades (TARTUCE, 2018, p. 2).

Diante disso, segundo Tartuce (2018, p. 2), "surgiu uma preocupação do legislador em buscar uma regularização possível dessas áreas, por institutos jurídicos diversos", isto é, em razão do cenário atual, bem como da expressiva quantidade de habitações sem registro, o legislador acabou autorizando outros institutos para formalizar esses imóveis adequadamente.

Frisa-se que o objetivo da regularização fundiária é legalizar, por meio da intervenção dos entes, as áreas ocupadas ilegalmente pela população, sobretudo os loteamentos que, por não atenderem aos preceitos legais, acabam se tornando irregulares ou clandestinos.

A diferença existente entre os loteamentos irregulares e os loteamentos clandestinos encontra-se no fato de que o primeiro possui um projeto que foi devidamente registrado pelo Municipal. Todavia, não foi aprovado ou passou a executar de forma diversa, não preenchendo os requisitos previstos na lei municipal. Já os loteamentos clandestinos são aqueles origina- 
dos sem o conhecimento do Poder Público, isto é, sem projeto prévio (CASTRO, 2002, p. 194).

Em outras palavras, Gazola (2008, p. 163) entende que os loteamentos clandestinos são aqueles que não possuem registros nem ao menos foram objeto de análise do poder público, enquanto os loteamentos irregulares são aqueles que possuem registros, mas não estão de acordo com os projetos implantados.

Ambas as formas de loteamento sofrem falta de infraestrutura, às vezes divisão correta dos lotes e, principalmente, não podem ser regularizados por meio do registro público.

Em face dessa impossibilidade de regularizar diretamente a titulação do imóvel, cabe ao Poder Judiciário, caso atendido os requisitos, tornar ambos os loteamentos legais, concedendo a titulação aos seus moradores.

\subsection{Legislação de Regularização Fundiária Urbana}

A definição da regularização fundiária é ampla e aberta, tratando-se de um conceito mais vasto que o disposto na Lei $\mathrm{n}^{\circ}$ 11.977/2009 e ao agora existente na atual Lei ${ }^{\circ}$ 13.465/2017. Todavia, em síntese, se refere ao cumprimento e à observância da legislação, dos meios ordinários e judiciais, buscando-se atingir a formalidade trazida pela lei e a concessão da segurança jurídica de uma unidade habitacional provinda, principalmente, de um loteamento ou de uma incorporação, seja ela irregular ou clandestina (PAIVA, 2017).

Em termos constitucionais, inexiste previsão expressa quanto à competência para legislar sobre moradia e saneamento básico. Entretanto, caso se observe apenas o teor da proteção da saúde, estaria presente uma competência concorrente, prevista no art. 24, XII, da CRFB/88. Caso observada a questão apenas pelo direito habitacional, a competência seria estadual, nos termos do art. $25, \S 1^{\circ}$, da CRFB/88, o que impediria 
o Município de legislar pela existência de interesse local (art. 30, I, da CRFB/88) ou em razão de necessidade de suplementar a legislação existente (art. 30, II, da CRFB/88). Por fim, e não menos importante, caberia à União instituir as diretrizes basilares para a habitação e o saneamento básico, conforme o constante do art. $21, \mathrm{XX}$, da CRFB/88, exercendo, portanto, uma competência legislativa apenas no âmbito genérico da matéria (BÉO et al., 2020, p. 184-185).

Desse modo, cabe verificar a legislação vigente em cada ente estatal.

\subsubsection{União}

No dia 22 de dezembro de 2016, o Presidente da República, Michel Temer, editou a Medida Provisória $n^{\circ} 759$ sobre regularização fundiária rural e urbana, liquidação de créditos concedidos aos assentados da reforma agrária e regularização fundiária no âmbito da Amazônia Legal, instituindo mecanismos para aprimorar a eficiência dos procedimentos de alienação de imóveis da União, e outras providências (BRASIL, 2017).

Encaminhada ao Congresso Nacional, passou pelo crivo da Comissão Mista de Deputados e Senadores e, em razão da expressa quantidade de emendas, o prazo regimental foi prorrogado, bem como promoveu 4 (quatro) audiências públicas interativas, sendo aprovada na Câmara dos Deputados no dia 28 de junho de 2017 e, no dia 11 de julho de 2017, houve a sanção presidencial que a converteu na Lei $n^{\circ} 13.465 / 2017$ (LOUREIRO; LOPES, 2019).

Essa nova legislação, conhecida como REURB, alterou diversos dispositivos como, por exemplo, da Lei no 8.629/1993, relativamente à regulamentação dos dispositivos constitucionais referentes à reforma agrária; da Lei $\mathrm{n}^{0}$ 13.001/2014 sobre a liquidação de créditos concedidos aos assentados da re- 
forma agrária; da Lei n ${ }^{\circ}$ 6.015/1973 de Registros Públicos; da Lei $n^{\circ}$ 10.406/2002 do Código Civil; da Lei ${ }^{\circ}$ 13.105/2015 do Código de Processo Civil; da Lei no 11.977/2009 sobre o Programa Minha Casa, Minha Vida (PMCMV) e a regularização fundiária de assentamentos localizados em áreas urbanas; da Lei $n^{\circ}$ 9.514/1997, que dispõe sobre o Sistema Financeiro Imobiliário; da Lei $n^{0} 11.124 / 2005$, que dispõe sobre o Fundo Nacional de Habitação de Interesse Social; da Lei $n^{0}$ 6.766/1979 sobre Parcelamento de Solo Urbano; da Lei $\mathrm{n}^{\mathrm{o}} 10.257 / 2001$, que regulamenta os arts. 182 e $183 \mathrm{da}$ CRFB/88; entre outras leis, medidas provisórias e decretos-leis, bem como revogou os dispositivos da Lei Complemen$\operatorname{tar} \mathrm{n}^{\circ} 76 / 1993$, que tratava sobre o procedimento contraditório especial para a desapropriação de imóvel rural, por interesse social, para fins de reforma agrária; e da Lei ${ }^{\circ} 13.347 / 2016$, que limitava o reajuste das receitas patrimoniais decorrentes das atualizações das plantas de valores (BRASIL, 2017).

Por conseguinte, a discursão acerca do desenvolvimento da legislação sobre regularização fundiária urbana foi o primeiro pilar a ser alcançado para combater o déficit habitacional. $\mathrm{Na}$ sequência, a dificuldade encontrada é como implantar as ideias trazidas pelo legislador.

A Lei $n^{0}$ 13.465/2017 (REURB), no seu art. 11, traz seus próprios conceitos para explicar e compreender o paradigma da regularização fundiária urbana, in verbis:

Art. 11. Para fins desta Lei, consideram-se:

I - núcleo urbano: assentamento humano, com uso e características urbanas, constituído por unidades imobiliárias de área inferior à fração mínima de parcelamento prevista na Lei $\mathrm{n}^{\mathrm{0}} 5.868$, de 12 de dezembro de 1972 , independentemente da propriedade do solo, ainda que situado em área qualificada ou inscrita como rural; II - núcleo urbano informal: aquele clandestino, irre- 
gular ou no qual não foi possível realizar, por qualquer modo, a titulação de seus ocupantes, ainda que atendida a legislação vigente à época de sua implantação ou regularização;

III - núcleo urbano informal consolidado: aquele de difícil reversão, considerados o tempo da ocupação, a natureza das edificações, a localização das vias de circulação e a presença de equipamentos públicos, entre outras circunstâncias a serem avaliadas pelo Município;

IV - demarcação urbanística: procedimento destinado a identificar os imóveis públicos e privados abrangidos pelo núcleo urbano informal e a obter a anuência dos respectivos titulares de direitos inscritos na matrícula dos imóveis ocupados, culminando com averbação na matrícula destes imóveis da viabilidade da regularização fundiária, a ser promovida a critério do Município; V - certidão de Regularização Fundiária (CRF): documento expedido pelo Município ao final do procedimento da REURB, constituído do projeto de regularização fundiária aprovado, do termo de compromisso relativo a sua execução e, no caso da legitimação fundiária e da legitimação de posse, da listagem dos ocupantes do núcleo urbano informal regularizado, da devida qualificação destes e dos direitos reais que lhes foram conferidos; VI - legitimação de posse: ato do poder público destinado a conferir título, por meio do qual fica reconhecida a posse de imóvel objeto da REURB, conversível em aquisição de direito real de propriedade na forma desta Lei, com a identificação de seus ocupantes, do tempo da ocupação e da natureza da posse; VII - legitimação fundiária: mecanismo de reconhecimento da aquisição originária do direito real de propriedade sobre unidade imobiliária objeto da REURB; VIII - ocupante: aquele que mantém poder de fato sobre lote ou fração ideal de terras públicas ou privadas em núcleos urbanos informais. (BRASIL, 2017, grifo nosso). 
Por meio dos conceitos delineados, é possível verificar que, dentre os entes públicos, o município se tornou o novo protagonista dessa legislação (TARTUCE, 2018, p. 6), cabendo, na ausência de atuação, aos Estados assumirem a função, e por último, a atuação da União.

Salienta-se ainda que os objetivos traçados pelo antigo modelo de regularização dada pela Lei ${ }^{\circ}$ 11.977/2009 estavam direcionados a conceder moradia e melhores condições de habitabilidade às pessoas de baixa renda (PONTES; BERTO, 2010). Com a conversão da Medida Provisória 759/2016 na Lei $\mathrm{n}^{\circ}$ 13.465/2017, houve a ampliação dos objetivos traçados pelo legislador, bem como dos possíveis beneficiados, conforme se verifica no art. 10 :

Art. 10. Constituem objetivos da REURB, a serem observados pela União, Estados, Distrito Federal e Municípios:

I - identificar os núcleos urbanos informais que devam ser regularizados, organizá-los e assegurar a prestação de serviços públicos aos seus ocupantes, de modo a melhorar as condições urbanísticas e ambientais em relação à situação de ocupação informal anterior;

II - criar unidades imobiliárias compatíveis com o ordenamento territorial urbano e constituir sobre elas direitos reais em favor dos seus ocupantes;

III - ampliar o acesso à terra urbanizada pela população de baixa renda, de modo a priorizar a permanência dos ocupantes nos próprios núcleos urbanos informais regularizados;

$\mathrm{V}$ - promover a integração social e a geração de emprego e renda;

$\mathrm{V}$ - estimular a resolução extrajudicial de conflitos, em reforço à consensualidade e à cooperação entre Estado e sociedade;

VI - garantir o direito social à moradia digna e às condições de vida adequadas; 
VII - garantir a efetivação da função social da propriedade;

VIII - ordenar o pleno desenvolvimento das funções sociais da cidade e garantir o bem-estar de seus habitantes; IX - concretizar o princípio constitucional da eficiência na ocupação e no uso do solo;

$\mathrm{X}$ - prevenir e desestimular a formação de novos núcleos urbanos informais;

$\mathrm{XI}$ - conceder direitos reais, preferencialmente em nome da mulher;

XII - franquear participação dos interessados nas etapas do processo de regularização fundiária. (BRASIL, 2017, grifo nosso).

Segundo Tartuce (2018, p. 5), a aprovação municipal da Regularização Fundiária Urbana, tratada no último comando do art. 10 da REURB, corresponde à aprovação urbanística do projeto de regularização fundiária, bem como à aprovação ambiental, se o Município tiver órgão ambiental capacitado. Caso não tenha profissional legalmente habilitado em seus quadros, caberá ao Estado realizar estudo de impactos ambiental (art. 12 , caput e $\S 1^{\circ}, 2^{\circ}$ e $4^{\circ}$ da Lei n. 13.465/17)

Ademais, de acordo com o art. 14, os legitimados para requerer a regularização são:

Art. 14. Poderão requerer a REURB:

I - a União, os Estados, o Distrito Federal e os Municípios, diretamente ou por meio de entidades da administração pública indireta;

II - os seus beneficiários, individual ou coletivamente, diretamente ou por meio de cooperativas habitacionais, associações de moradores, fundações, organizações sociais, organizações da sociedade civil de interesse público ou outras associações civis que tenham por finalidade atividades nas áreas de desenvolvimento urbano ou regularização fundiária urbana; 
III - os proprietários de imóveis ou de terrenos, loteadores ou incorporadores;

IV - a Defensoria Pública, em nome dos beneficiários hipossuficientes; e

V - o Ministério Público. (BRASIL, 2017, grifo nosso).

No que tange à forma de aquisição, a Lei no ${ }^{\circ}$ 13.465/2017 elenca vários institutos jurídicos que podem ser empregados, como: usucapião, concessão de direito real de uso, doação, compra e venda, desapropriação por interesse social, perempção, intervenção do poder público em parcelamento clandestino ou irregular, requisição, entre outros. Contudo, neste ponto, é importante frisar dois novos instrumentos dispostos pelo projeto de lei: a legitimação fundiária e a legitimação de posse.

Segundo Paiva (2017) e o art. 25 da REURB, a legitimação fundiária é uma nova forma de aquisição originária imobiliária, permitindo ao ocupante legítimo adquirir plenamente determinado imóvel por ato do poder público, sem quaisquer ônus ou vínculo com o antigo proprietário. Nesse caso, deve ser o novo proprietário integrante de núcleo urbano informal consolidado existente antes de 22 de dezembro de 2016.

No que lhe diz respeito, a legitimação de posse é um instituto jurídico de uso exclusivo para imóveis particulares (art. $25, \S 2^{\circ}$ ), destinado a conferir título, por ato do poder público, diante do reconhecimento da posse, da identificação dos ocupantes, do tempo da ocupação e da sua natureza, reconhecendo, nesse caso, a usucapião.

Em suma, é possível, por meio da lei federal, a configuração da legitimação fundiária, desde que o imóvel individual ou loteamento encontre-se, até 22/12/2016, ocupado, com edificações, vias de circulação e presença de equipamentos públicos, como, por exemplo, água potável e energia elétrica. Juntamente, deve atender aos termos do art. 183 da CRFB/88, ou seja, possuir por mais de 5 (cinco) anos imóveis com área de até 
$250 \mathrm{~m}^{2}$ (duzentos e cinquenta metros quadrados) para fins de moradia, para serem avaliados e ter a titulação realizada diretamente pelo Poder Executivo municipal.

\subsubsection{Estado}

O Estado de Santa Catarina, por sua vez, possui a Resolução n. 8, de 9 de junho de 2014, do Conselho da Magistratura do Tribunal de Justiça de Santa Catarina (CM), alterada pelo art. $2^{\circ}$ da Resolução CM n. 4, de 11 de março de 2019, instrumentalizando a forma de dar cumprimento à legislação federal e não descumpri-la.

A referida resolução instituiu o projeto "Lar Legal" no âmbito do Poder Judiciário do Estado de Santa Catarina, objetivando viabilizar a regularização de ocupações fundiárias não planejadas e não autorizadas administrativamente. Ocupações essas consolidadas fisicamente, mas precárias de registro, conferindo aos seus residentes moradia condigna, com acesso a equipamentos e serviços públicos básicos, conforme a aplicação dos direitos à propriedade, à moradia e à dignidade da pessoa humana.

Trata-se, portanto, de iniciativa de desburocratização em prol do exercício da cidadania, que parte do pressuposto de "que a atual função do Direito não se restringe à solução de conflitos de interesses e a busca de segurança jurídica, mas em criar condições para a valorização da cidadania e promoção da justiça social", conforme consta na exposição de motivos da citada Resolução. (SANTA CATARINA, 2019c, grifo do autor).

A Resolução tratou de elencar todo o arcabouço legislativo necessário para fundamentar o procedimento e dar agilidade ao programa "Lar Legal" e, dessa forma, garantir celeridade, dignidade e acesso das pessoas de baixa renda ao Poder Judiciário, sem afrontar a legislação federal. 
Outrossim, o procedimento de jurisdição voluntária adotada exige a verificação da existência ou não de Área de Preservação Permanente (APP) ou área de risco, facilitando a regularização fundiária e permitindo a resolução coletivamente à questão, a fim de evitar inúmeros processos de usucapião.

Desse modo, o art. $1^{\circ}$ da resolução prevê:

Art. $1^{\circ} \mathrm{O}$ reconhecimento do domínio sobre imóvel urbano ou urbanizado, integrante de loteamento ou desmembramento (fracionamento ou desdobro) não autorizado ou executado sem a observância das determinações do ato administrativo de licença, localizado em área urbana consolidada, implantada e integrada à cidade, excluídas as áreas de risco ambiental ou de preservação permanente que não se enquadrem nos termos do artigo 54 da Lei n. 11.977, de 7 de julho de 2009, em favor de pessoas preponderantemente de baixa renda, poderá ser obtido conforme o disposto nesta resolução. (Redação dada pelo art. $1^{\circ}$ da Resolução CM n. 2 de 11 de maio de 2015). (SANTA CATARINA, 2015, grifo nosso).

Observa-se do dispositivo que o reconhecimento de domínio do imóvel urbano não permite que se autorize edificações em áreas de risco ambiental ou de preservação permanente. Caso se ingresse com demanda em que haja essa violação, haverá a extinção da ação, sem resolução do mérito (SANTA CATARINA, 2020a).

Outro requisito indispensável é que o loteamento irregular ou clandestino possua situação consolidada. Outrossim, considera-se área urbana consolidada a parcela de território urbano que apresente, no mínimo, dois equipamentos de infraestrutura e que a ocupação pacífica ocorra a pelo menos 5 (cinco) anos, conforme o art. $1^{\circ}, \S 1^{\circ}$, da Resolução 8/2014, in verbis:

$\S 1^{\circ}$ Considera-se área urbana consolidada a parcela do território urbano com densidade demográfica 
considerável, malha viária implantada e, ainda, no mínimo, dois equipamentos de infraestrutura urbana (drenagem de águas pluviais, esgotamento sanitário, abastecimento de água, distribuição de energia elétrica, limpeza urbana, coleta e manejo de resíduos sólidos) implantados, cuja ocupação, de forma mansa e pacífica, há, pelo menos, cinco anos, a natureza das edificações existentes, dentre outras situações peculiares, indique a irreversibilidade da posse e induza ao domínio. (SANTA CATARINA, 2019b, grifo nosso).

Ressalta-se que a comprovação de situação consolidada poderá se dar por qualquer documento hábil (art. $1^{\circ}, \S 2^{\circ}$ ). Ademais, no campo processual, o Magistrado poderá oficiar o ente municipal para averiguar a existência de infraestrutura no loteamento, informando, por exemplo, a existência de pavimentação asfáltica, abastecimento de água potável, distribuição de energia elétrica, rede de esgoto, entre outros.

Frisa-se que a declaração de regularidade fundiária não afasta as responsabilidades do proprietário, do loteador ou mesmo do Poder Público, sem prejudicar as medidas cíveis, criminais ou administrativas cabíveis (SANTA CATARINA, 2019c).

É necessário, ainda, no ingresso da ação voluntária judicial, a juntada de documentos arrolados no art. $4^{\circ}$ da Resolução, quais sejam:

Art. $4^{\circ}$ A petição inicial deverá ser instruída com:

I - certidão atualizada da matrícula do imóvel objeto do loteamento ou desmembramento ou certidão do registro de imóveis comprobatória de que não está registrado; II - certidão negativa de ação real ou reipersecutória referente ao imóvel expedida pelo respectivo ofício do registro de imóveis;

III - certidão de ônus reais relativos ao imóvel;

IV - planta simplificada da área, com as respectivas divisas, acompanhada do memorial descritivo assinado por 
profissional habilitado e com a devida Anotação de Responsabilidade Técnica - ART, que contenha:

a) descrição sucinta da área urbana consolidada, com as suas características, fixação da zona ou zonas de uso predominante e identificação e qualificação disponível dos confrontantes e de seus cônjuges, se casados forem; (Redação dada pelo art. $2^{\circ}$ da Resolução CM n. 2 de 11 de maio de 2015)

b) indicação e descrição precisa de cada lote objeto do loteamento ou desmembramento, com suas características e confrontações, localização, área, logradouro, número e de sua designação cadastral, se houver, com menção ao nome dos ocupantes e dos confrontantes internos; c) indicação das vias e existentes e enumeração dos equipamentos urbanos, comunitários e serviços públicos ou de utilidade pública já existentes na área urbana consolidada;

d) indicação das áreas públicas que passarão ao domínio do município;

$\mathrm{V}$ - nome, domicílio, nacionalidade, estado civil, profissão, número de inscrição no Cadastro de Pessoas Físicas do Ministério da Fazenda do(s) proprietário(s) e de seu(s) cônjuges(s), se casados forem; (Redação dada pelo art. $2^{\circ}$ da Resolução CM n. 2 de 11 de maio de 2015) VI - cópia dos documentos pessoais e dos comprobatórios da compra e venda ou da titularidade da posse do imóvel;

VII - declaração dos órgãos competentes, preferencialmente municipais, de que não se trata de área de risco ambiental ou de preservação permanente nos termos do artigo $1^{\circ}$; (Redação dada pelo art. $2^{\circ}$ da Resolução CM n. 2 de 11 de maio de 2015)

VIII - lei municipal autorizadora, na hipótese de imóvel público ou sob intervenção do Poder Público.

Parágrafo único. Tratando-se de pedido formulado apenas pelos interessados, não acompanhando a petição 
inicial qualquer documento demonstrando a anuência prévia do município, deverá ser intimado para manifestar seu interesse no prazo de 10 (dez) dias. (Redação dada pelo art. $2^{\circ}$ da Resolução CM n. 2 de 11 de maio de 2015). (SANTA CATARINA, 2019b, grifo nosso).

Os demais dispositivos tratam da sequência de atos processuais a serem seguidos no âmbito do Poder Judiciário, após o recebimento da Petição Inicial. Além dos atos já frisados, há a necessidade de intimação, anuência, cumprimento e respeito aos prazos indicados na resolução. Assim, ao final, o Magistrado, sob o critério de legalidade estrita, adotará uma solução conveniente ou oportuna (SANTA CATARINA, 2019c).

Para finalizar, é importante consignar que, surgindo futuramente eventuais prejudicados, estes não restarão desamparados, uma vez que, nos termos do art. 14 da Resolução, "o registro poderá ser retificado ou anulado, parcialmente ou na totalidade, por sentença em processo contencioso, ou por efeito julgado em ação de anulação ou de declaração de nulidade de ato jurídico, ou de julgado sobre fraude à execução". (SANTA CATARINA, 2019c).

\subsubsection{Município}

No que lhe concerne, o Prefeito do Município de Herval d'Oeste, Nelson Guindani, promulgou a Lei Complementar $n^{\circ}$ 337/2016, por meio da qual instituiu o Programa de Regularização Fundiária denominada "Lar Legal".

Colhe-se dessa Lei Complementar que a autoridade política traçou como objetivos gerais, no art. $1^{\circ}$, o reconhecimento do domínio do imóvel urbano ou a ser urbanizado, que seja oriundo de loteamento ou desmembramento não autorizado pelo entre municipal, ou executado sem observar os ditames legais. 
Conforme já verificado no art. $1^{\circ}, \S 1^{\circ}$, da Resolução $n^{\circ}$ 8/2014 da CM, a área urbana consolidada será aquela parcela do território urbano que, além de apresentar malha viária, possua, no mínimo, dois equipamentos de infraestrutura e ocupação de forma mansa e pacífica há, no mínimo, 5 (cinco) anos. Veja-se:

Art. $1^{\circ}$ Fica instituído, no Município de Herval d' Oeste, o programa de regularização fundiária, denominado LAR LEGAL, que tem por objetivo o reconhecimento do domínio sobre imóvel urbano ou urbanizado, integrante de loteamento ou desmembramento (fracionamento ou desdobro) não autorizado ou executado sem a observância das determinações do ato administrativo de licença, localizado em área urbana consolidada, implantada e integrada à cidade, excluídas as áreas de risco ambiental ou de preservação permanente definidas em lei, em favor de pessoas preponderantemente de baixa renda.

$\S 1^{\circ}$ Considera-se área urbana consolidada a parcela do território urbano com densidade demográfica considerável, malha viária implantada e, ainda, no mínimo, dois equipamentos de infraestrutura urbana (drenagem de águas pluviais, esgotamento sanitário, abastecimento de água, distribuição de energia elétrica, limpeza urbana, coleta e manejo de resíduos sólidos) implantados, cuja ocupação, de forma mansa e pacífica, há, pelo menos, cinco anos, a natureza das edificações existentes, dentre outras situações peculiares, indique a irreversibilidade da posse e induza ao domínio.

$\S 2^{\circ}$ Para aferir a situação jurídica consolidada, serão suficientes quaisquer documentos hábeis a comprová-la, notadamente provenientes do Poder Público, especialmente do Município.

$\S 3^{\circ}$ A declaração do domínio em favor do adquirente não isenta nem afasta qualquer das responsabilidades do proprietário ou loteador, tampouco importa em prejuízo à adoção das medidas cíveis, criminais ou administra- 
tivas, cabíveis contra o faltoso. (HERVAL D’OESTE, 2016, grifo nosso).

O ente municipal, no art. $2^{\circ}$, delimitou os objetivos específicos a serem atendidos pelo Programa "Lar Legal":

Art. $2^{\circ}$ Constituem objetivos específicos do programa de regularização fundiária, a ser coordenado e executado pela Secretaria Municipal de Habitação:

I - Regularizar e legalizar a propriedade da área e/ou lote, visando a escrituração e registro imobiliário;

II - Regularizar loteamentos e desmembramentos não autorizados ou executados sem a observância das determinações do ato administrativo de licença, localizados em áreas consolidadas;

III - Possibilitar o acesso dos munícipes às políticas sociais públicas. (HERVAL D’OESTE, 2016, grifo nosso).

Salienta-se que, no art. $3^{\circ}$ da Lei Complementar, o Município ratificou o procedimento empregado pelo Estado por meio da edição da Resolução 8/2014. Veja-se:

Art. $3^{\circ}$ Para o alcance dos objetivos desta lei, o Município aderirá aos procedimentos previstos na Resolução $\mathrm{CM} \mathrm{n}^{\circ} 8$, de 9 de junho de 2014, do Conselho da Magistratura do Tribunal de Justiça do Estado de Santa Catarina, o qual altera o Projeto "Lar Legal", instituído pela Resolução $\mathrm{CM} \mathrm{n}^{\circ}$ 11, de 11 de agosto de 2008, ou norma posterior que vier a substituí-la. (HERVAL D'OESTE, 2016, grifo nosso).

Por fim, verifica-se que a Lei Complementar editada pelo Município de Herval d'Oeste configura uma cópia quase exata da Resolução expedida pelo Conselho da Magistratura do Tribunal de Justiça de Santa Catarina (CM). Assim, o Município indica aos munícipes que, caso desejarem ingressar com ações judiciais para regularização fundiária, deverão se adequar à Resolução já existente e ratificada. 


\subsection{Casos concretos e a sua aplicação jurídica}

Neste momento, passa-se à análise das decisões jurisprudenciais existentes no Tribunal de Justiça de Santa Catarina, verificando os Acórdãos formados pelos desembargadores no exame da temática.

Observa-se, no julgamento da Apelação Cível n. 031280320.2015.8.24.0018, da Comarca de Chapecó, que a sentença foi de extinção, sem resolução de mérito, pois o Magistrado entendeu que a Resolução n. 8/2014 CM apenas tutelava direitos coletivos. Entretanto, após a apelação, a $2^{\mathrm{a}}$ instância manteve incólume a sentença proferida, todavia, mediante fundamento diverso, pois é possível o pleito pela associação de moradores ou pelos próprios interessados (art. $3^{\circ}$ ), portanto a Resolução atende a direitos individuais homogêneos. $\mathrm{O}$ Tribunal entendeu que os apelantes demonstraram, na juntada de documentos, a existência de escritura pública de compromisso de compra e venda e de autorização do ente público municipal para a efetivação do loteamento, não existindo nenhuma alegação de execução sem observância do ato administrativo de licença. Dessa forma, deveria ser reconhecida a falta de interesse de agir no caso, porque não há enquadramento adequado às previsões da Resolução CM n. 8/2014 (SANTA CATARINA, 2020b).

Outra situação que ensejou e ensejará a extinção da ação ocorre quando o imóvel se encontra, parcial ou totalmente, inserido em área de preservação permanente. Nesse caso, haverá a inviabilidade da regularização fundiária por meio do Programa Lar Legal, em razão da sua exclusão pelo art. $1^{\circ}$ da Resolução CM n. 8/2014, bem como pela violação de dispositivo de Lei federal. No julgado, verifica-se que tanto a Engenheira Ambiental quanto o Instituto Municipal do Meio Ambiente (IMMA) de Jaguaruna declararam que a área objeto de regularização estava parcialmente inserida em Área de Preservação Permanente 
(APP), conforme a Lei federal n ${ }^{\circ} 12.651 / 2012$ e/ou a Resolução CONAMA n ${ }^{\circ}$ 303/2002 (SANTA CATARINA, 2020a).

Verifica-se ainda, na jurisprudência catarinense, que, caso o imóvel objeto da demanda, seja loteamento ou desmembramento irregular, possua estudo ambiental realizado por profissional habilitado, apresente ART (Anotação de Responsabilidade Técnica) e demonstre que o imóvel não está em situação de área de preservação permanente ou de risco, não precisa apresentar estudo socioambiental e projeto de regularização fundiária (SANTA CATARINA, 2019b).

Colhe-se do inteiro teor do Acórdão citado que, na sessão realizada em 11/5/2016, o Grupo de Câmaras de Direito Público julgou, com efeito vinculante (art. 947, § $3^{\circ}$, do CPC/15 e art. 555, § $1^{\circ}$, do CPC/73), o Incidente de Assunção de Competência n. 0002958-59.2014.8.24.0022, pelo qual estabeleceu a seguinte tese (Tema n. 1 - revista):

A apresentação de provas fornecidas pelo Poder Público, desde que elaboradas por profissional técnico com anotação de responsabilidade, e capazes de demonstrar a real situação do imóvel objeto da regularização registraria, revela-se suficiente para evidenciar que a pretensão exordial de registro do bem em matrícula imobiliária própria, no contexto do Projeto 'Lar Legal', criado pelo Provimento n. 37/99, da Corregedoria-Geral da Justiça de Santa Catarina, atendeu aos requisitos normativos e legais de estilo. (TJSC, Apelação n. 000295859.2014.8.24.0022, de Curitibanos, rel. Des. João Henrique Blasi, Grupo de Câmaras de Direito Público, j. 1409-2016). (SANTA CATARINA, 2019b).

É importante frisar que, embora as normas elaboradas pelos entes priorizem as demandas propostas por pessoas carentes e preponderantemente de baixa renda, não significa que, caso esse requisito não seja atendido, haverá restrição no amparo legal. 
Isto é, caso não seja demonstrada a situação de hipossuficiência de todos os proprietários/requerentes, por si só, não acarretará impedimento na declaração do direito do interessado em ter o domínio do imóvel, sobretudo em face da inexistência de amparo regulamentar ou legal (SANTA CATARINA, 2019a).

Ante o exposto, verifica-se que cabe aos Tribunais suprir as dúvidas não respondidas pelas normas legais criadas pelos entes públicos e pela discordância das partes quanto à interpretação do Magistrado de $1^{\circ}$ Grau.

\section{CONCLUSÃO}

Inicialmente, é importante concluir que a regularização fundiária é o cerne de diversas indagações envolvendo os direitos constitucionais da propriedade, da moradia e da dignidade da pessoa humana, bem como abrange questões sobre saúde, segurança jurídica e desigualdade social.

Esse instrumento, que apesar de aparentar possuir apenas aplicação coletiva em razão do uso em propriedades decorrentes de loteamentos irregulares e clandestinos, também atende a direitos individuais homogêneos, permitindo a titulação da propriedade por outras formas de aquisição, além da conhecida usucapião.

Por derradeiro, as normas vigentes visam, como exposto, resolver os graves problemas habitacionais que acometem o Brasil, buscando regularizar as propriedades e promovendo o desenvolvimento de condições de vida digna aos cidadãos.

É importante frisar que, em Santa Catarina, o Poder Judiciário possui grande papel nessa regularização, pois foi edita a Resolução n. 8/2014 do CM estruturando as regras para o ingresso da ação voluntária para regular os imóveis, principalmente os provindos de loteamentos ou desmembramentos irregulares e clandestinos. 
Nesse sentido, as questões que não forem dirimidas no processo judicial, na primeira instância, passaram pelo crivo dos desembargadores que firmaram os seus entendimentos a respeito das interpretações efetuadas quando não claras ou não respondidas pelas normas legais.

Em síntese, o primeiro ponto para iniciar a regularização das habitações das cidades parte-se da legislação e de normas de aplicação, pois o que já se encontra construído, mediante requisitos, deve ser regulado. Frisa-se, ainda, que possibilita as novas propriedades passarem pelo crivo dos entes para se adequarem previamente, para questões como essa não abarrotarem o judiciário. Todavia, não cabe apenas ao judiciário dirimir essa crise, mas ao Poder Executivo desenvolver políticas públicas para fomentar a regularização das futuras habitações.

\section{REFERÊNCIAS}

ALMEIDA, Guilherme Assis de et al. Art. 5, II, CF. In: MACHADO, Costa et al.(org.). Constituição Federal interpretada: artigo por artigo, parágrafo por parágrafo. 11. ed. Baueri/SP: Manole, 2020. E-book. BÉO, Cintia Regina et al. Art. $5^{\circ}$, incisos XX e XXI. In: MACHADO, Costa et al. (org.). Constituição Federal interpretada: artigo por artigo, parágrafo por parágrafo. 11. ed. Baueri/SP: Manole, 2020. E-book.

BRASIL. [Constituição (1988)]. Constituição da República Federativa do Brasil 1988. Brasília. DF: Presidência da República, 1988. Disponível em: http://www.planalto.gov.br/ccivil_03/constituicao/constituicaocompilado.htm. Acesso em: 14 maio 2020.

BRASIL. Lei n.13.465, de 11 de julho de 2017. Dispõe sobre a regularização fundiária rural e urbana, sobre a liquidação de créditos concedidos aos assentados da reforma agrária e sobre a regularização fundiária no âmbito da Amazônia Legal. Institui mecanismos para aprimorar a eficiência dos procedimentos de alienação de imóveis da União; e dá outras providências. Diário Oficial da União, Brasília, DF, 8 ago. 2017. Disponível em: http://www.planalto.gov.br/ccivil_03/_Ato20152018/2017/Lei/L13465.htm. Acesso em: 13 maio 2020. 
CASTRO, Sandra Costa Siaines de. Loteamentos irregulares e clandestinos: a cidade e a lei. Rio de Janeiro: Lumen Juris, 2002.

FERRAZ FILHO, José Francisco Cunha et al. Art. $5^{\circ}$, incisos XXII e XXIII. In: MACHADO, Costa et al (org.). Constituição Federal interpretada: artigo por artigo, parágrafo por parágrafo. 11. ed. Baueri/ SP: Manole, 2020. E-book.

GAZOLA, Patrícia Marques. Concretização do direito à moradia digna: teoria e prática. Belo Horizonte: Fórum, 2008.

HERVAL D'OESTE. Lei Complementar $\mathrm{n}^{\circ} 337$, de 8 de março de 2016. Diário Oficial do Município. Herval D’Oeste, SC, 18 abr. 2016. Disponível em: https://leismunicipais.com.br/a1/sc/h/herval-do-oeste/ lei-complementar/2016/34/337/lei-complementar-n-337-2016-institui-o-programa-de-regularizacao-fundiaria-denominado-lar-legal-no-municipio-de-herval-d-oeste?q=337. Acesso em: 1 maio 2020.

LOUREIRO, Antônio José Cacheado; LOPES, Tiago Oliveira. Regularização fundiária urbana: breve análise à luz da Lei n. 13.465/2017. Revista Jus Navigandi, Teresina, ano 24, n. 5788, maio 2019. Disponível em: https:/jus.com.br/artigos/72429. Acesso em: 26 mar. 2020.

MELO, Marco Aurélio Bezerra de et al. Art. $5^{\circ}$, XXII e XXIII, CF. In: CONSTITUIÇÃO Federal Comentada. Rio de Janeiro: Forense, 2018. cap. 2. E-book.

PAIVA, João Pedro Lamana. Regularização fundiária: reflexos sobre as inovações legislativas. In: ENCONTRO NACIONAL DOS OFICIAIS DE REGISTRO DE IMÓVEIS DO BRASIL, 44., 2017. Anais [...]. Curitiba: Instituto de Registro Imobiliário do Brasil - IRIB, 2017. Disponível em: http://irib.org.br/files/palestra/xliv-tema-06-joao1.pdf. Acesso em: 15 maio 2020.

SANTA CATARINA. Tribunal de Justiça. Apelação Cível no 030333034.2015.8.24.0010. Relatora: Vera Lúcia Ferreira Copetti, 12 de dezembro de 2019. Jurisprudência Catarinense, Florianópolis, 5 dezembro 2019a. Disponível em: http://busca.tjsc.jus.br/jurisprudencia/html.do?$\mathrm{q}=\&$ only_ementa $=\&$ frase $=\& \mathrm{id}=\mathrm{AABAg} 7 \mathrm{AAHAAI} 2 \mathrm{OwAAS} \&$ categoria=acordao_5. Acesso em: 14 maio 2020.

SANTA CATARINA. Tribunal de Justiça. Apelação Cível no 000094468.2015.8.24.0022. Relator: Jaime Ramos, 22 de fevereiro de 2019. 
Jurisprudência Catarinense, Florianópolis, 19 de fevereiro de 2019b. Disponível em: http://busca.tjsc.jus.br/jurisprudencia/html.do?$\mathrm{q}=$ \&only_ementa $=\&$ frase $=\& \mathrm{id}=\mathrm{AABAg} 7 \mathrm{AAFAAFYSeAAK} \&$ categoria=acordao_5. Acesso em: 14 maio 2020.

SANTA CATARINA. Tribunal de Justiça. Resolução CM n. 4 de 11 de março de 2019. Altera a Resolução CM n. 8 de 9 de junho de 2014 e a Resolução CM n. 1 de 11 de setembro de 2017 e dá outras providências. Diário da Justiça, Florianópolis, n. 3016, 12 de mar. 2019c. Disponível em: http://busca.tjsc.jus.br/buscatextual/integra.do?cdSistema $=1 \&$ cdDocumento $=173955 \& \mathrm{cdCategoria}=1 \& \mathrm{q}=$ Resolu $\% \mathrm{E} 7 \% \mathrm{E} 3 \mathrm{o} \% 20$ n. $\% 208 \&$ frase $=$ regulariza $\% E 7 \% E 3 o \&$ excluir $=\&$ qualquer $=\&$ pro$\mathrm{x} 1=\&$ prox $2=\&$ proxc $=$. Acesso em: 01 maio 2020.

SANTA CATARINA. Tribunal de Justiça. Apelação Cível no 030122692.2016.8.24.0282. Relator: Henry Petry Junior, 12 de maio de 2020. Jurisprudência Catarinense, Florianópolis, 14 maio 2020a. Disponível em: http://busca.tjsc.jus.br/jurisprudencia/html.do?q=regulari$\mathrm{za} \% \mathrm{E} 7 \% \mathrm{E} 3 \mathrm{o} \% 20$ fundi $\% \mathrm{E} 1 \mathrm{ria} \&$ only_ementa $=\&$ frase $=\& \mathrm{id}=\mathrm{AABA}-$ g7AAIAACeJKAAA\&categoria=acordao_5. Acesso em: 14 maio 2020.

SANTA CATARINA. Tribunal de Justiça. Apelação Cível no 031280320.2015.8.24.0018. Relator: Henry Petry Junior,12 de maio de 2020b. Jurisprudência Catarinense, Florianópolis, 14 maio 2020b. Disponível em: http://busca.tjsc.jus.br/jurisprudencia/html.do?q=regulari$\mathrm{za} \% \mathrm{E} 7 \% \mathrm{E} 3 \mathrm{0} \% 20$ fundi $\% \mathrm{E} 1 \mathrm{ria} \& \quad$ only_ementa $=\&$ frase $=\& \mathrm{id}=\mathrm{AABA}-$ g7AAIAACeJKAAH\&categoria=acordao_5. Acesso em: 14 maio 2020.

SANTIN, Janaína Rigo; COMIRAN, Rafaela. Direito Urbanístico e Regularização Fundiária. Revista de Direito da Cidade, Rio de Janeiro, v. 10, n. 3, jul. 2018. DOI: http://dx.doi.org/10.12957/rdc.2018.32734. Disponível em: https://www.e-publicacoes.uerj.br/index.php/rdc/article/view/32734. Acesso em: 15 maio 2020.

SOUZA, Sérgio Iglesias Nunes de. Direito à moradia e de habitação: análise comparativa e suas implicações teóricas e práticas com os direitos da personalidade. São Paulo: Revista dos Tribunais, 2004.

TARTUCE, Flávio. A Lei da Regularização Fundiária (Lei 13.465/2017): análise inicial de suas principais repercussões para o direito de propriedade: análise inicial de suas principais repercussões para o direito de propriedade. Pensar - Revista de Ciências Jurídi- 
cas, Fortaleza, v. 23, n. 03, 2018. DOI: http://dx.doi.org/10.5020/23172150.2018.7800. Disponível em: https://periodicos.unifor.br/rpen/article/download/7800/pdf. Acesso em: 30 abr. 2020.

VITORINO, Odair Márcio et al. Art. $6^{\circ}$, CF. In: MACHADO, Costa et al. (org.). Constituição Federal interpretada: artigo por artigo, parágrafo por parágrafo. 11. ed. Baueri/SP: Manole, 2020. E-book.

Recebido em: 22/05/2020

Aprovado em: 19/07/2020 